\title{
Efeito da Densidade de Corrente e Temperatura na Área Superficial do Dióxido de Manganês Eletrolítico
}

\author{
A.J.B. Dutra; I.C.F. Almeida \\ Universidade Federal do Rio de Janeiro \\ COPPE/UFRJ-PEMM \\ CP: 68505. Ilha do Fundão, Rio de Janeiro, RJ. CEP: 21941-972 \\ e-mail: adutra@metalmat.ufrj.br, izaura@metalmat.ufrj.br
}

\begin{abstract}
RESUMO
Neste artigo foi estudado o efeito da densidade de corrente e da temperatura na produção de dióxido de manganês eletrolítico (DME) a partir de soluções ácidas de sulfato de manganês por meio de voltametria de varredura linear, microscopia eletrônica de varredura e medidas de área superficial (BET). Foi observado que na temperatura de $65^{\circ} \mathrm{C}$ a produção de DME foi limitada pelo fenômeno de passivação dos anodos de titânio e que, a $90^{\circ} \mathrm{C}$ este efeito era substancialmente reduzido. Foi também verificado que o aumento da densidade de corrente e a diminuição da temperatura proporcionaram um aumento significativo na área superficial específica do depósito de DME. A maior área superficial, de $168 \mathrm{~m}^{2} / \mathrm{g}$, foi obtida com uma densidade de corrente de $8 \mathrm{~mA} / \mathrm{cm}^{2}$, em solução $0,34 \mathrm{M}$ de $\mathrm{H}_{2} \mathrm{SO}_{4}$ a $65^{\circ} \mathrm{C}$, enquanto que a menor, de $52 \mathrm{~m}^{2} / \mathrm{g}$, foi obtida com uma densidade de corrente de $4 \mathrm{~mA} / \mathrm{cm}^{2}$, na mesma solução, a $90^{\circ} \mathrm{C}$.
\end{abstract}

Palavras chaves: Dióxido de manganês eletrolítico, área superficial, voltametria.

\section{The Effect of Current Density and Temperature on the Surface Area of Electrolytic Manganese Dioxide}

\section{ABSTRACT}

In this paper the effect of current density and temperature on the production of electrolytic manganese dioxide (EMD) from acidic manganese sulfate solutions was studied by linear sweep voltammetry, scanning electron microscopy and surface area measurements (BET). At $65^{\circ} \mathrm{C}$, it was observed that the EMD production was limited by the passivation of the titanium anodes, but at $90^{\circ} \mathrm{C}$ this effect was substantially reduced. It was also verified that the increase of current density and the decrease of temperature lead to a considerable increase of the specific surface area of the EMD deposit. The higher surface area, $168 \mathrm{~m}^{2} / \mathrm{g}$, was obtained with a current density of $8 \mathrm{~mA} / \mathrm{cm}^{2}$, in a $0.34 \mathrm{M} \mathrm{H}_{2} \mathrm{SO}_{4}$ solution, at $65^{\circ} \mathrm{C}$, while the smaller, $52 \mathrm{~m}^{2} / \mathrm{g}$, was obtained with a current density of $4 \mathrm{~mA} / \mathrm{cm}^{2}$, in the same solution, at $90^{\circ} \mathrm{C}$.

Keywords: Electrolytic manganese dioxide, surface area, voltammetry.

\section{INTRODUÇÃO}

O dióxido de manganês eletrolítico é amplamente utilizado tanto na fabricação de pilhas primárias do tipo Leclanché (zinco-carbono) e alcalinas como na obtenção do espinélio $\left(\mathrm{LiMn}_{2} \mathrm{O}_{4}\right)$, componente das pilhas recarregáveis de lítio. As pilhas do tipo zinco carbono foram inventadas pelo químico Georges Leclanché em 1866 e são utilizadas até os dias de hoje, com pequenas variações. As tentativas de sua substituição por pilhas com desempenho superior e por pilhas secundárias (recarregáveis), esbarram no baixo custo e na alta confiabilidade das pilhas do tipo Leclanché [1], mantendo-as no mercado para as aplicações mais comuns. Uma variação pilha zinco-carbono é a pilha alcalina, onde o cloreto de amônio, que constituía o eletrólito da pilha zinco-carbono, foi substituído pelo hidróxido de potássio. A Tabela 1 sintetiza a eletroquímica das pilhas acima mencionadas. 
Tabela 1: Eletroquímica das pilhas primárias a base de dióxido de manganês $[\underline{1}, \underline{2}]$.

\begin{tabular}{|c|c|c|c|}
\hline Tipo & Reação catódica & Reação anódica & Eletrólito \\
\hline Zn-C & $2 \mathrm{MnO}_{2}+\mathrm{H}_{2} \mathrm{O}+2 \mathrm{e}^{-} \rightarrow$ & $\mathrm{Zn} \rightarrow \mathrm{Zn}^{2+}+2 \mathrm{e}^{-}$ & $\mathrm{NH}_{4} \mathrm{Cl} / \mathrm{ZnCl}_{2} / \mathrm{MnO}_{2} /$ \\
(Leclanché) & $\mathrm{Mn}_{2} \mathrm{O}_{3}+2 \mathrm{OH}^{-}$ & & $\mathrm{C}($ pó$) /$ amido úmidos \\
\hline Alcalina & $2 \mathrm{MnO}_{2}+\mathrm{H}_{2} \mathrm{O}+2 \mathrm{e}^{-} \rightarrow$ & $\mathrm{Zn}+2 \mathrm{OH}^{-} \rightarrow \mathrm{ZnO}+\mathrm{H}_{2} \mathrm{O}+2 \mathrm{e}^{-}$ & $\begin{array}{c}\mathrm{NH} \mathrm{Cl}_{4} / \mathrm{ZnCl}_{2} / \mathrm{MnO}_{2} / \\
\mathrm{KOH} / \mathrm{C}(\text { pó}) \text { úmidos }\end{array}$ \\
& $2 \mathrm{MnO}(\mathrm{OH})+2 \mathrm{OH}^{-}$ & & \\
\hline
\end{tabular}

Embora o dióxido de manganês ocorra na natureza na forma de pirolusita, existem no mundo poucas jazidas deste mineral com grau de pureza suficientemente elevado para a fabricação de pilhas. Assim, uma alternativa para a obtenção do $\mathrm{MnO}_{2}$ é a sua síntese, que pode ser química ou eletroquímica. A obtenção de

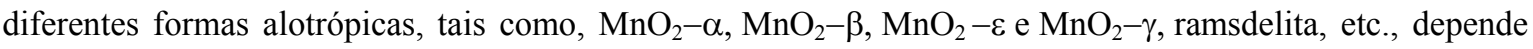
do método de síntese, sendo que as formas $\mathrm{MnO}_{2}-\varepsilon$ e $\mathrm{MnO}_{2}-\gamma$, geralmente, são constituintes de depósitos produzidos a partir da eletrólise de soluções contendo íons $\mathrm{Mn}^{2+}$ [2]. Além disso, o dióxido de manganês produzido eletroliticamente é mais condutivo e possui menos defeitos de rede cristalina que o respectivo mineral, sendo, portanto mais adequado para a fabricação de pilhas []ㅡ.

A qualidade das pilhas de Leclanché e das pilhas alcalinas de $\mathrm{Zn} / \mathrm{MnO}_{2}$ está diretamente ligada à descarga parcial do catodo, cujo material é composto, em sua maioria, por $\mathrm{MnO}_{2}$. Entre os métodos de produção de dióxido de manganês para uso em pilhas, destaca-se a eletrodeposição anódica de $\mathrm{MnO}_{2}$ em meio sulfato, conforme a reação (1) [4]. Isto se deve ao fato do emprego de sulfato de manganês na produção eletrolítica de DME apresentar vantagens, como: a minimização dos problemas de corrosão, alta eficiência de corrente e, também, a presença de poros no produto final que influencia no ciclo de descarga da pilha.

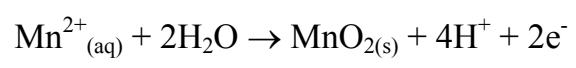

Na produção de DME em meio sulfato, podem ser utilizados diferentes tipos de anodos, tais como, a grafita, as ligas de chumbo e antimônio (eletrodo mais convencional) e, o titânio, que, atualmente, é considerado o material mais apropriado []].

Muito esforço tem se destinado à determinação das condições de produção de DME, com o intuito de se verificar qual a influência dos parâmetros de eletrólise na qualidade do produto final. A densidade de corrente, que depende do material do anodo, podendo atingir valores na faixa de $5,0 \mathrm{~mA} / \mathrm{cm}^{2}$ a $25,0 \mathrm{~mA} / \mathrm{cm}^{2}$, com anodos de titânio e soluções de concentrações de sulfato de manganês variando de 0,15 a $2,0 \mathrm{M}$ e de ácido sulfúrico na faixa de 0,2 a $0,5 \mathrm{M} \mathrm{H}_{2} \mathrm{SO}_{4}$, em temperaturas entre 90 e $97^{\circ} \mathrm{C}$. Nestas condições, valores de eficiência de corrente de aproximadamente $90 \%$ foram obtidos por Rethinaraj e Visvanathan [ㅁ]. Também pode ser destacada que a eletrodeposição de DME sobre titânio em densidade de corrente de $15 \mathrm{~mA} / \mathrm{cm}^{2}$ a $90^{\circ} \mathrm{C}$, em meio de 2,0M de $\mathrm{MnSO}_{4}$ e $0,30 \mathrm{M}$ de $\mathrm{H}_{2} \mathrm{SO}_{4}$, levou a uma quantidade apreciável de $\mathrm{MnO}_{2}-\varepsilon$, forma alotrópica empregada como precursora do espinélio $\mathrm{LiMn}_{2} \mathrm{O}_{4}$, que é usado na fabricação de pilhas secundárias de lítio []].

A temperatura é um parâmetro relevante nas características do depósito de DME, pois influencia a capacidade de carga $(\mathrm{mA} \cdot \mathrm{h} / \mathrm{g})$ das pilhas com catodos confeccionados com DME. Foi observado que as pilhas contendo DME produzido a $120^{\circ} \mathrm{C}$ e a $115^{\circ} \mathrm{C}$ obtiveram maior capacidade de carga que aquelas contendo DME produzido a $100^{\circ} \mathrm{C}$, devido ao decréscimo do potencial anódico que proporcionou um maior crescimento dos cristais [7]. A forma de crescimento dos cristais de $\mathrm{MnO}_{2}$, e consequentemente a sua área superficial, pode apresentar influência sobre a taxa de descarga das pilhas primárias e, portanto, sobre a sua durabilidade, sendo dessa forma um fator importante na especificação do dióxido de manganês eletrolítico usado na fabricação de pilhas.

O objetivo do presente trabalho foi o de avaliar a influência da densidade de corrente e da temperatura na área superficial e morfologia do dióxido de manganês eletrolítico depositado sobre anodos de titânio em soluções compostas de sulfato de manganês e ácido sulfúrico.

\section{PROCEDIMENTO EXPERIMENTAL}

O estudo potenciostático foi realizado utilizando um potenciostato EG\&G PAR modelo 273A conectado a um microcomputador com o programa M270 para a elaboração das curvas voltamétricas. A célula eletrolítica utilizada nos testes voltamétricos foi confeccionada em vidro Pirex, com um volume de 
250mL, e circundada por uma camisa térmica para circulação de água com um banho termostático, de modo que a temperatura da solução permanecesse constante e controlada $\left( \pm 1^{\circ} \mathrm{C}\right)$. O eletrodo de trabalho foi uma chapa de titânio com área superficial de $1 \mathrm{~cm}^{2}$, o contra-eletrodo uma tela de aço inoxidável AISI 304 dobrada, de modo a fornecer uma área superficial elevada. Como referência foi usado o eletrodo $\mathrm{Ag} / \mathrm{AgCl}$, cujo potencial em relação ao eletro padrão de hidrogênio é de $0,222 \mathrm{~V}$, por ser o mais adequado para temperaturas elevadas []. O eletrólito foi uma solução ácido sulfúrico $0,34 \mathrm{M}$ ou $0,68 \mathrm{M}$ com concentrações de sulfato de manganês variando de 0,09 a $1 \mathrm{M}$.

As eletrólises a corrente constante foram realizadas na mesma célula a $65^{\circ} \mathrm{C}$ e a $90^{\circ} \mathrm{C}$, com carga elétrica constante de $384 \mathrm{~mA} . h$., porém, com um anodo de $28 \mathrm{~cm}^{2}$ de área e dois catodos constituídos de tela de aço inoxidável. Nesta etapa, foi utilizada uma fonte de corrente contínua, um multímetro Keithley 179 e um eletrômetro Keithley 617 para monitorar a corrente e a tensão. Após as eletrólises, depósito de $\mathrm{MnO}_{2}$ foi analisado por microscopia eletrônica de varredura e posteriormente, removido da chapa de titânio e seco para ser, analisado por difração de raios-X e BET, para determinação da área superficial do dióxido de manganês.

\section{RESULTADOS E DISCUSSÃO}

\subsection{Estudo Voltamétrico}

Voltametrias de varredura linear realizadas com uma velocidade de varredura de potencial de $2,5 \mathrm{mV} / \mathrm{s}$ a $65^{\circ} \mathrm{C}$, sem e com agitação são apresentadas nas Figuras 1 e 2 respectivamente. Pode ser observado, em ambas as figuras, que na ausência de $\mathrm{Mn}^{2+}$ a densidade de corrente permaneceu muito próxima à zero, mesmo em potenciais muito elevados (curva a), indicando uma possível passivação do anodo de titânio. Com a introdução de quantidades crescentes de $\mathrm{Mn}^{2+}$ (curvas b-e) pode ser observado um rápido crescimento da corrente em potenciais superiores a $1100 \mathrm{mV}$, indicando o início da deposição do dióxido de manganês. Adicionalmente, foi verificada, a partir de $1600 \mathrm{mV}$, a presença de picos de densidade de corrente seguidos de patamares cujos níveis crescem com o aumento da concentração de $\mathrm{Mn}^{2+}$ presente na solução. Pela comparação das Figuras 1 e 2, pode ser notado que a agitação da solução não levou os picos de densidade de corrente a níveis significativamente mais elevados, como era de se esperar num processo controlado por transporte de massa. Este comportamento indica que a queda na densidade de corrente pode estar associada à passivação dos anodos de titânio, que, portanto, limitam a produção do dióxido de manganês.

As Figuras 3 e 4 apresentam voltametrias de varredura linear realizadas com uma velocidade de varredura de potencial de $2,5 \mathrm{mV} / \mathrm{s}$ a $90^{\circ} \mathrm{C}$, sem e com agitação respectivamente. Pode ser observado um comportamento análogo ao das duas figuras anteriores, porém, os picos de densidade de corrente observados se apresentaram de forma mais discreta e a níveis consideravelmente mais elevados, seguidos de um novo crescimento da mesma, particularmente nos testes realizados sem agitação do eletrólito. Esse comportamento indica que o fenômeno de passivação se apresenta de forma mais amena em temperaturas mais elevadas e o segundo crescimento da corrente pode ser atribuído à geração de oxigênio, de acordo com a reação (2). O fenômeno de passivação também foi observado por LAURINDO et al. [4]], os quais identificaram que este era minimizado quando a temperatura de eletrodeposição de dióxido de manganês foi aumentada.

$$
2 \mathrm{H}_{2} \mathrm{O} \rightarrow \mathrm{O}_{2}+4 \mathrm{H}^{+}+4 \mathrm{e}^{-}
$$

Durante as voltametrias não foi observado desprendimento anódico de oxigênio em quantidades significativas, fato corroborado pela baixíssima densidade de corrente, mesmo para potenciais elevados, como pode ser observado na curva (a) das Figuras 1-4. 


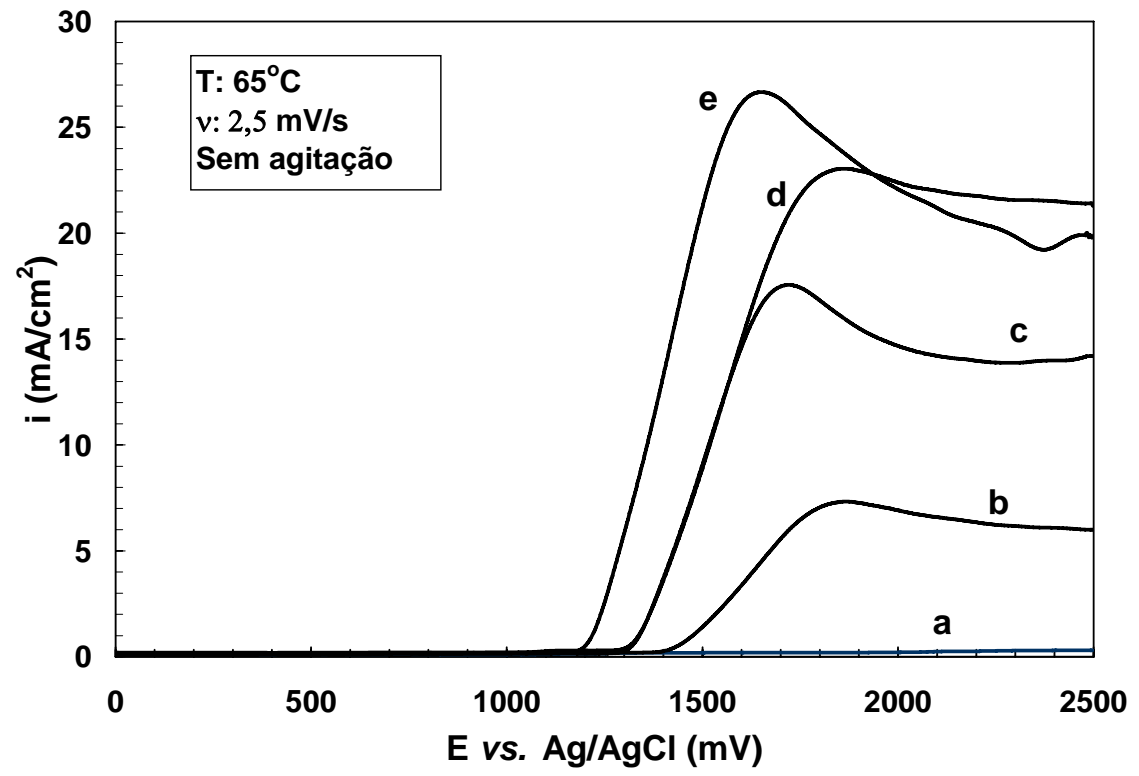

Figura 1: Voltametrias de varredura linear, a $65^{\circ} \mathrm{C}$, com anodo de $\mathrm{Ti}$, em $\mathrm{H}_{2} \mathrm{SO}_{4} 0,34 \mathrm{M}$ e as seguintes concentrações de $\mathrm{MnSO}_{4}:$ (a): 0,00 M, (b): 0,09 M ; (c): 0,60 M ; (d): 0,89 M; (e): 1,00 M.

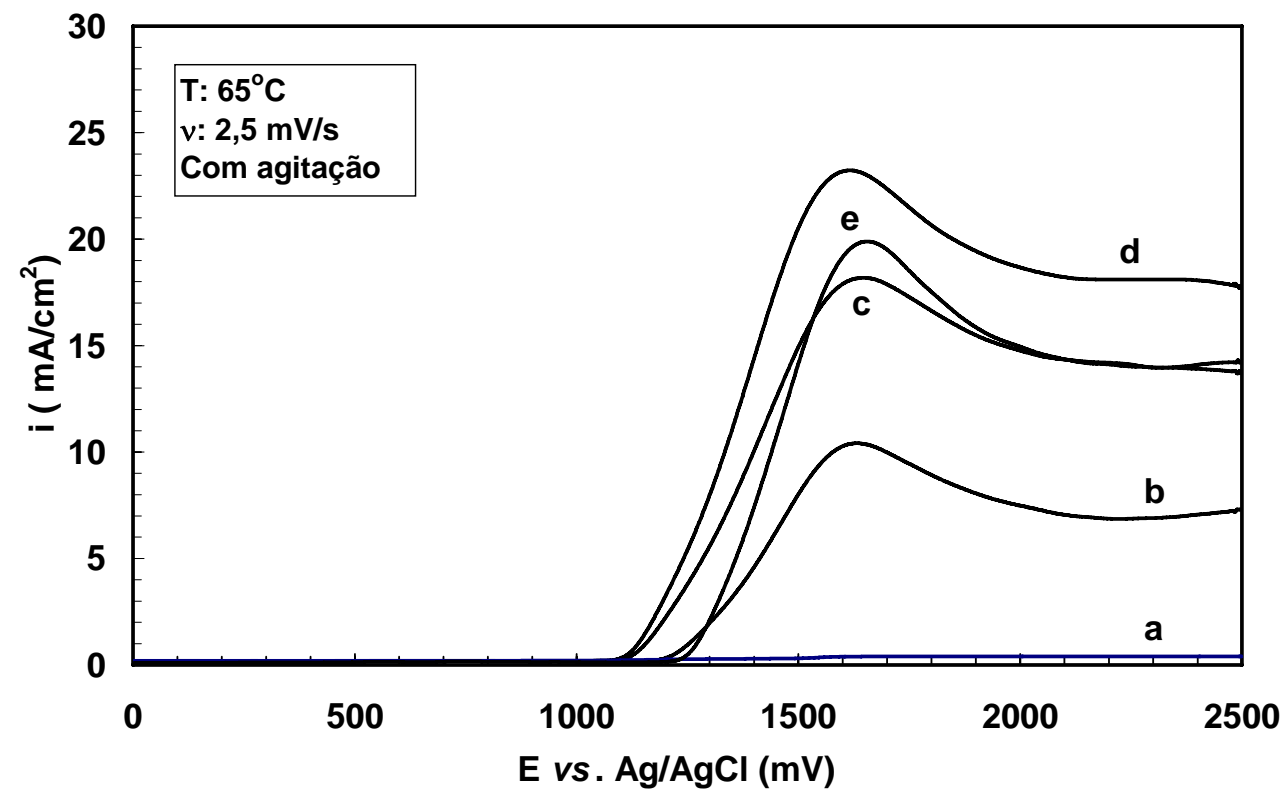

Figura 2: Voltametrias de varredura linear, a $65^{\circ} \mathrm{C}$, com anodo de $\mathrm{Ti}$, em $\mathrm{H}_{2} \mathrm{SO}_{4} 0,34 \mathrm{M}$ e as seguintes concentrações de $\mathrm{MnSO}_{4}$ : (a): 0,00 M, (b): 0,09 M ; (c): 0,60 M ; (d): 0,89 M; (e): 1,00 M. 


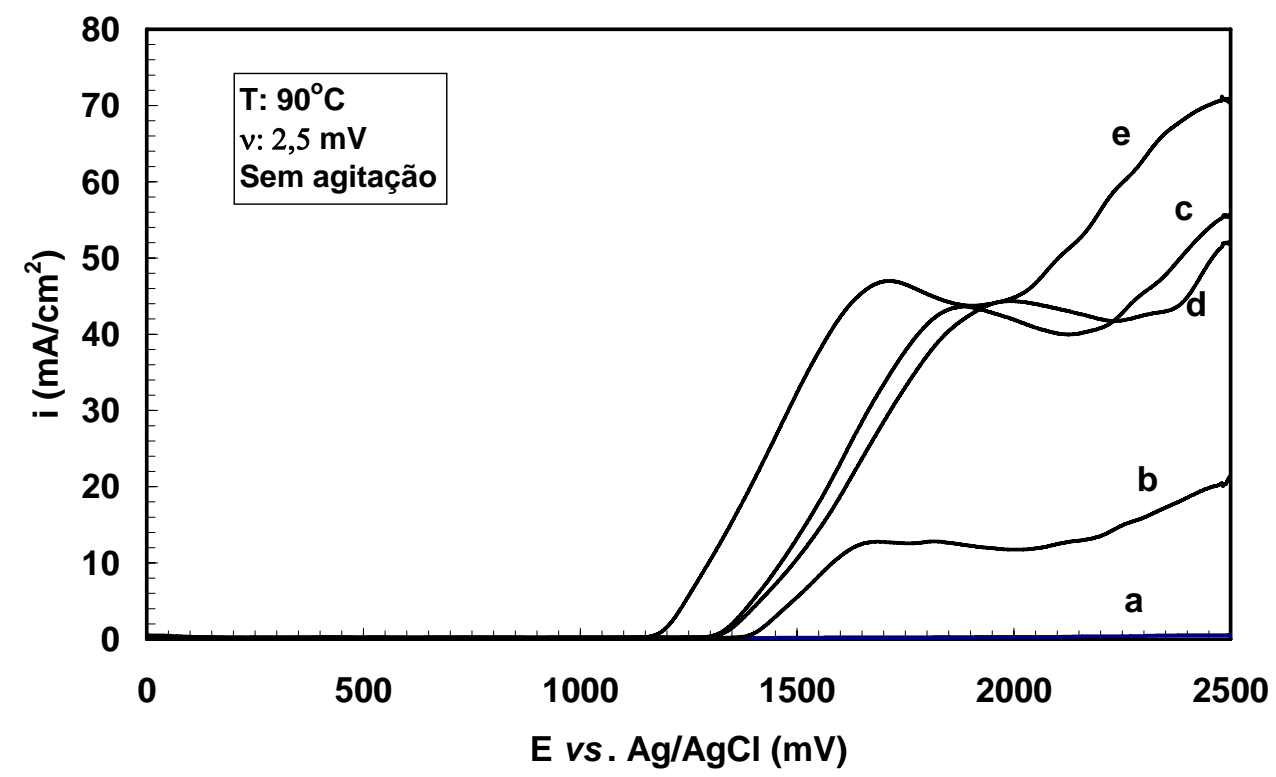

Figura 3: Voltametrias de varredura linear, a $90^{\circ} \mathrm{C}$, com anodo de Ti, em $\mathrm{H}_{2} \mathrm{SO}_{4} 0,34 \mathrm{M}$ e as seguintes concentrações de $\mathrm{MnSO}_{4}$ : (a): 0,00 M, (b): 0,09 M ; (c): 0,60 M ; (d): 0,89 M; (e): 1,00 M.

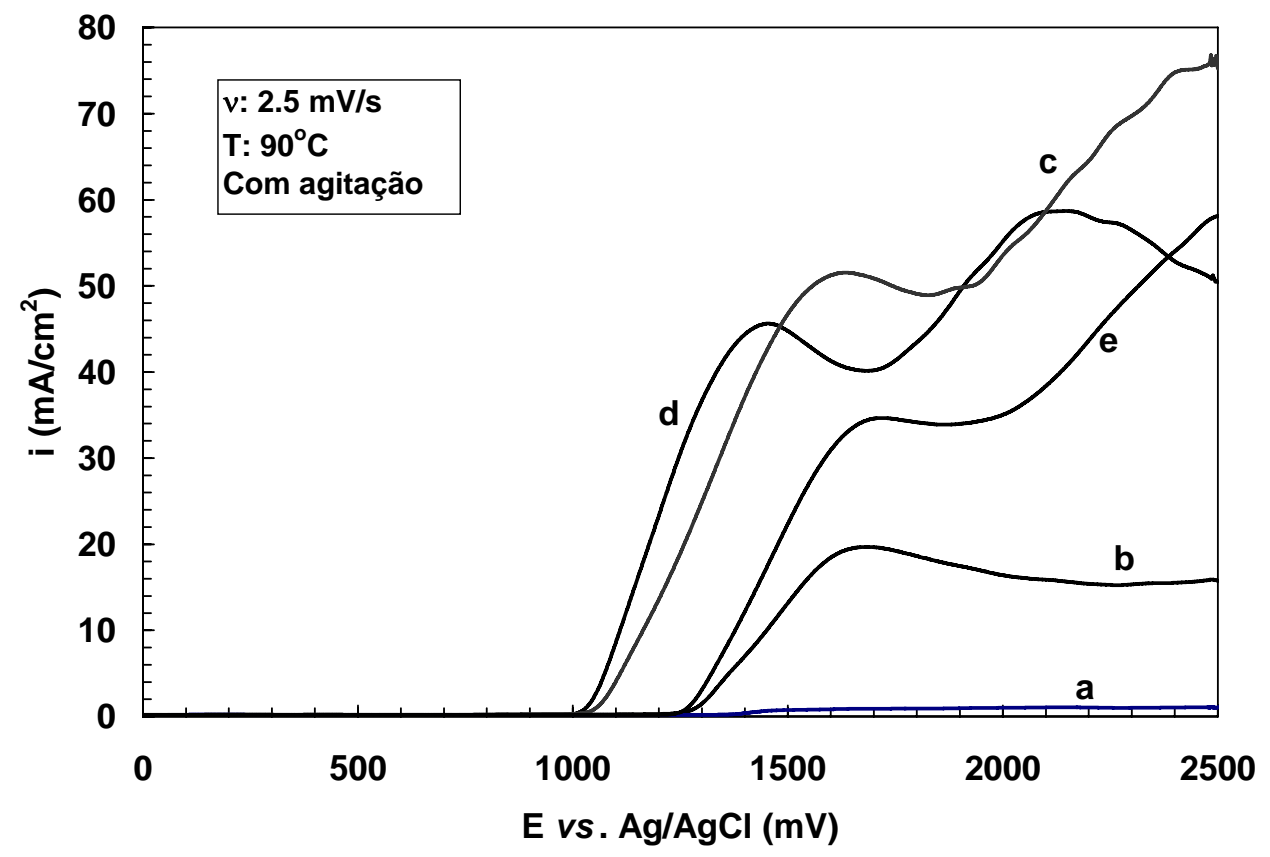

Figura 4: Voltametrias de varredura linear, a $90^{\circ} \mathrm{C}$, com anodo de Ti, em $\mathrm{H}_{2} \mathrm{SO}_{4} 0,34 \mathrm{M}$ e as seguintes concentrações de $\mathrm{MnSO}_{4}$ : (a): 0,00 M, (b): 0,09 M ; (c): 0,60 M ; (d): 0,89 M; (e): 1,00 M.

A influência da concentração de ácido sulfúrico e temperatura nas voltametrias de varredura linear com anodo de Ti, em solução $1,00 \mathrm{M}$ de $\mathrm{MnSO}_{4}$, sem agitação do eletrólito é apresentada na Figura 5. Pode ser observado que, tanto a 65 como a $90^{\circ} \mathrm{C}$, o aumento da concentração de ácido sulfúrico de 0,34 para 0,68 $\mathrm{M}$ dificulta a oxidação do $\mathrm{Mn}^{2+}$ a $\mathrm{MnO}_{2}$, deslocando as curvas de polarização para potenciais mais elevados. 


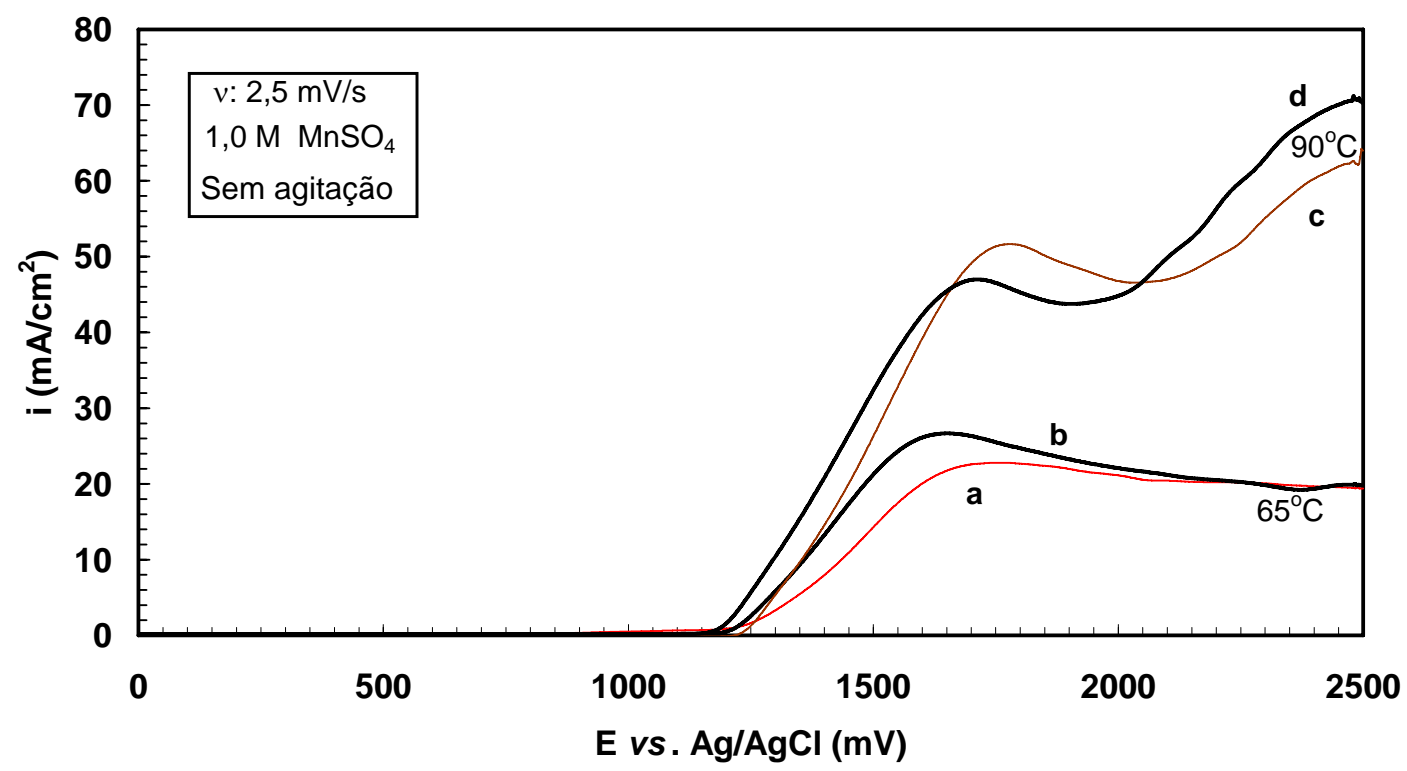

Figura 5: Influência da temperatura e concentração de ácido sulfúrico nas voltametrias de varredura linear com anodo de Ti, em solução 1,00 $\mathrm{M}$ de $\mathrm{MnSO}_{4}$, sem agitação do eletrólito. (a) $\mathrm{H}_{2} \mathrm{SO}_{4} 0,68 \mathrm{M}$ e $65^{\circ} \mathrm{C}$;

(b) $\mathrm{H}_{2} \mathrm{SO}_{4} 0,34 \mathrm{M}$ e $65^{\circ} \mathrm{C}$; (c) $\mathrm{H}_{2} \mathrm{SO}_{4} 0,68 \mathrm{M}$ e $90^{\circ} \mathrm{C}$; (d) $\mathrm{H}_{2} \mathrm{SO}_{4} 0,34 \mathrm{M}$ e $65^{\circ} \mathrm{C}$.

\subsection{Avaliação das Características Estruturais do Depósito}

As áreas superficiais do dióxido de manganês produzido por eletrólise de solução $1 \mathrm{M}$ de $\mathrm{MnSO}_{4}$, sem agitação, com carga constante de $384 \mathrm{~mA} \cdot \mathrm{h}$, em oito condições diferentes, são apresentadas na Tabela 2. Em todos os testes, a eficiência de corrente obtida foi de aproximadamente $100 \%$. Tal fato, também, foi observado por Matsuki e colaboradores [2], os quais obtiveram eficiências de corrente de 101 e 111, em densidades de corrente de $10 \mathrm{~mA} / \mathrm{cm}^{2}$ e $15 \mathrm{~mA} / \mathrm{cm}^{2}$, e sendo também corroborada por Ghaemi e Binder [7], em estudo realizado na faixa de densidade de corrente de $5 \mathrm{~mA} / \mathrm{cm}^{2}$ a $37,5 \mathrm{~mA} / \mathrm{cm}^{2}$. Os valores de eficiência de corrente superiores a 100\%, eventualmente encontrados podem ser atribuídos à presença de água no depósito de dióxido de manganês. Pode ser observado na Tabela 2 que densidades de corrente elevadas e baixas temperaturas favorecem o aumento da área superficial específica do dióxido de manganês. O aumento da densidade de corrente é o fator mais relevante no aumento da área superficial específica do dióxido de manganês produzido, pois leva à formação de estruturas dendríticas no depósito, como mostram as Figuras 6 e 7. A diminuição da temperatura também favorece o aumento da área superficial do $\mathrm{MnO}_{2}$ devido à diminuição da densidade de corrente limite para a oxidação do $\mathrm{Mn}^{2+}$, como mostram as voltametrias das Figuras 1-5. Assim, em temperaturas mais baixas trabalha-se numa fração mais elevada da densidade de corrente limite, o que favorece a obtenção de depósitos mais rugosos e até mesmo, em casos extremos, dendríticos e pulverulentos [9]. A influência da concentração de ácido na estrutura do depósito não é muito evidente, apresentando um comportamento mais complexo, que depende tanto da temperatura como também do nível de densidade de corrente, já que as curvas de polarização para duas concentrações de ácido distintas, apresentadas na Figura 5, se cruzam, tanto na temperatura de $65^{\circ} \mathrm{C}$ como na de $90^{\circ} \mathrm{C}$. Além disso, a $65^{\circ} \mathrm{C}$ a densidade de corrente limite é mais elevada para a menor concentração de ácido, enquanto que a $90^{\circ} \mathrm{C}$ o comportamento oposto foi observado. De qualquer forma, as medidas de área superficial, apresentadas na Tabela 2 indicam uma tendência de aumento na área superficial do depósito com a elevação da concentração de ácido.

Os depósitos com maiores áreas superficiais foram observados nos testes (3) e (4), que apresentaram uma estrutura claramente dendrítica, como mostram as Figuras 6(3) e 7(4), para depósitos obtidos com $8 \mathrm{~mA} / \mathrm{cm}^{2}$ a $65^{\circ} \mathrm{C}$. Já nas Figuras 6(5) e 7(6) podem ser observados que os depósitos de $\mathrm{MnO}_{2}$ com menor área superficial, obtidos com $4 \mathrm{~mA} / \mathrm{cm}^{2}$ a $90^{\circ} \mathrm{C}$, apresentam um aspecto razoavelmente liso, com aspecto botrióide, característico de óxidos de manganês hidratados. 
Tabela 2: Áreas superficiais específicas obtidas sob as diferentes condições de eletrólise utilizadas na produção de dióxido de manganês eletrolítico a partir de soluções de 1,0 $\mathrm{M}$ de $\mathrm{MnSO}_{4}$ sem agitação.

\begin{tabular}{|c|c|c|c|c|}
\hline Teste & $\begin{array}{c}\text { Temperatura } \\
\left({ }^{\circ} \mathrm{C}\right)\end{array}$ & $\begin{array}{c}\text { Densidade de corrente } \\
\left(\mathrm{mA} / \mathbf{c m}^{2}\right)\end{array}$ & $\begin{array}{c}\text { Concentração de } \mathrm{H}_{2} \mathrm{SO}_{4} \\
(\mathrm{M})\end{array}$ & $\begin{array}{c}\text { Área superficial } \\
\left(\mathrm{m}^{2} / \mathrm{g}\right)\end{array}$ \\
\hline 1 & 65 & 4 & 0,34 & $133,9 \pm 0,2$ \\
\hline 2 & 65 & 4 & 0,68 & $153,4 \pm 1,4$ \\
\hline 3 & 65 & 8 & 0,34 & $168,0 \pm 1,0$ \\
\hline 4 & 65 & 8 & 0,68 & $166,1 \pm 1,1$ \\
\hline 5 & 90 & 4 & 0,34 & $51,8 \pm 0,1$ \\
\hline 6 & 90 & 4 & 0,68 & $70,1 \pm 0,6$ \\
\hline 7 & 90 & 8 & 0,34 & $85,3 \pm 0,4$ \\
\hline 8 & 90 & 8 & 0,68 & $141,0 \pm 0,7$ \\
\hline
\end{tabular}

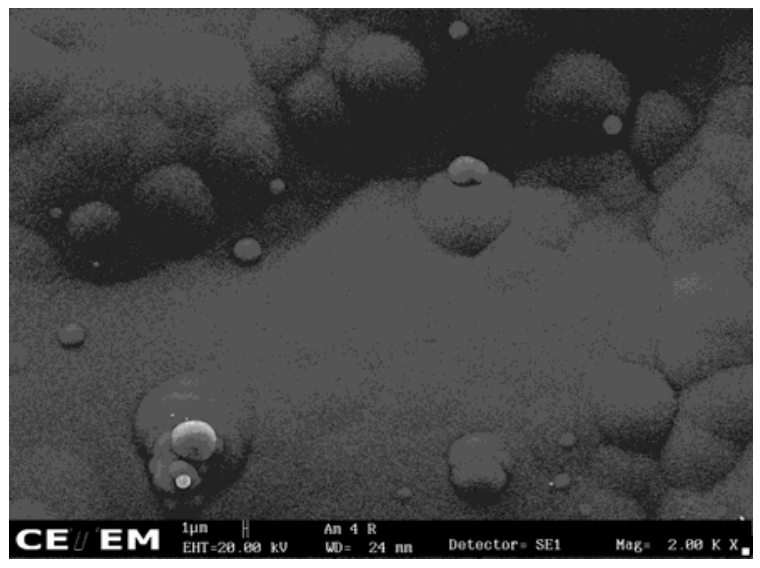

(1): $\mathrm{T}: 65^{\circ} \mathrm{C} ; \mathrm{i}: 4 \mathrm{~mA} / \mathrm{cm}^{2}$.

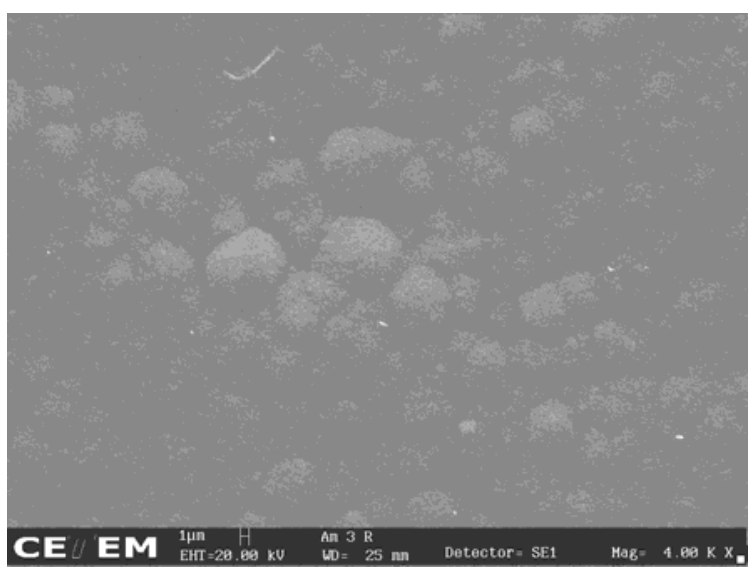

(5): $\mathrm{T}: 90^{\circ} \mathrm{C} ; \mathrm{i}: 4 \mathrm{~mA} / \mathrm{cm}^{2}$.

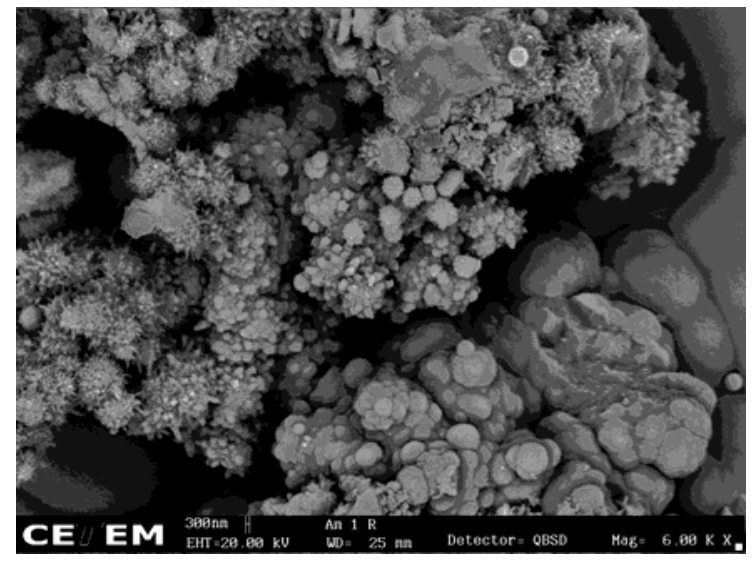

(3): $\mathrm{T}: 65^{\circ} \mathrm{C} ; \mathrm{i}: 8 \mathrm{~mA} / \mathrm{cm}^{2}$.

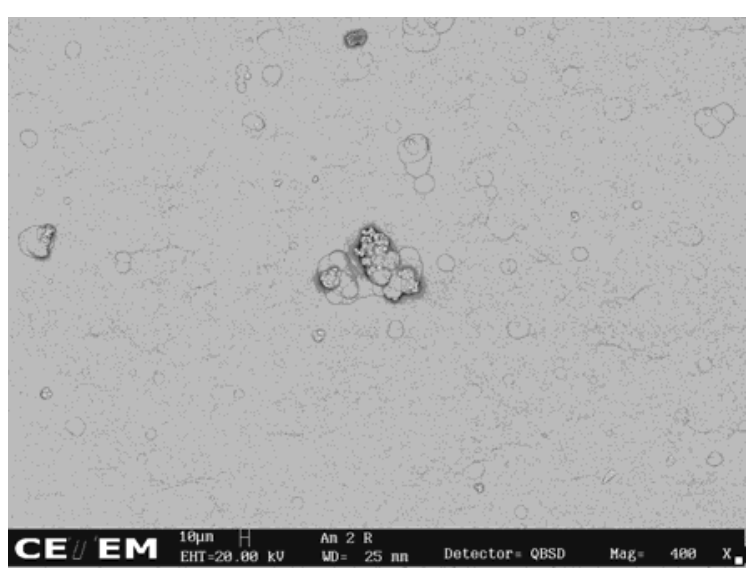

(7): $\mathrm{T}: 90^{\circ} \mathrm{C} ; \mathrm{i}: 8 \mathrm{~mA} / \mathrm{cm}^{2}$.

Figura 6: Influência da temperatura e densidade de corrente na estrutura do $\mathrm{MnO}_{2}$ obtido em solução $1 \mathrm{M}$ de $\mathrm{MnSO}_{4}$ e $0,34 \mathrm{M}$ de $\mathrm{H}_{2} \mathrm{SO}_{4}$. 


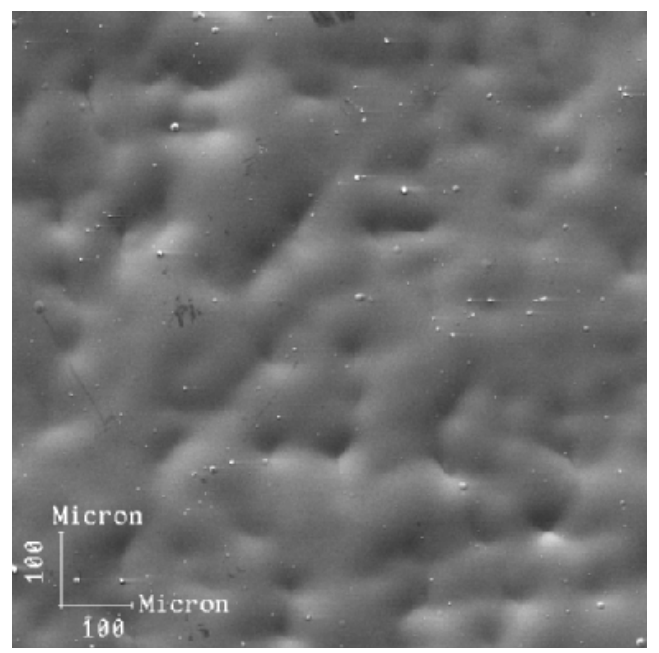

(2): T: $65^{\circ} \mathrm{C} ; \mathrm{i}: 4 \mathrm{~mA} / \mathrm{cm}^{2}$.

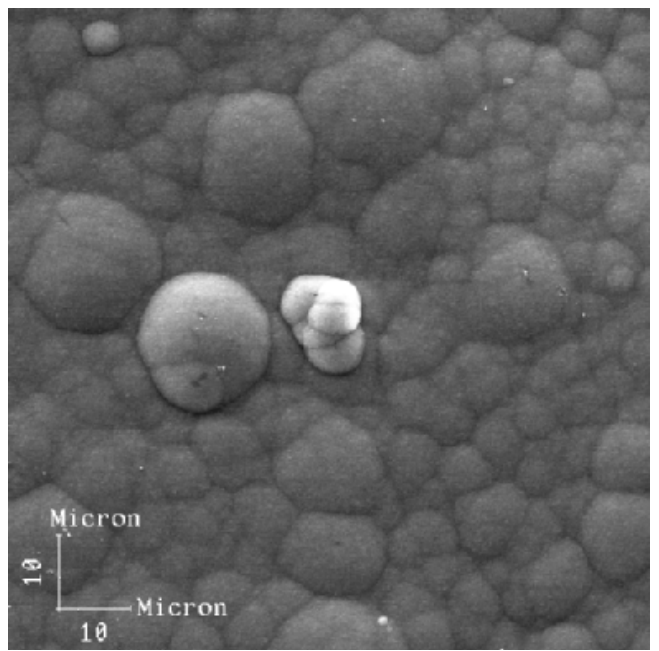

(6): $\mathrm{T}: 90^{\circ} \mathrm{C} ; \mathrm{i}: 4 \mathrm{~mA} / \mathrm{cm}^{2}$.

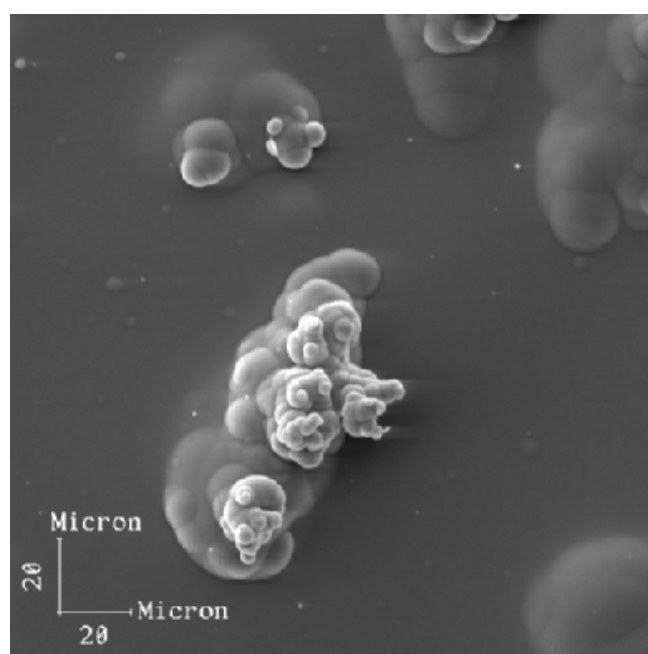

(4): $\mathrm{T}: 65^{\circ} \mathrm{C} ; \mathrm{i}: 8 \mathrm{~mA} / \mathrm{cm}^{2}$.

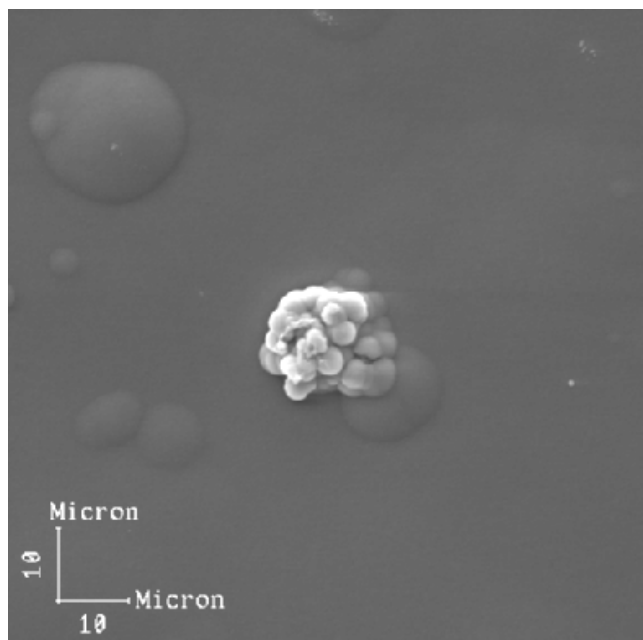

(8): T: $90^{\circ} \mathrm{C} ; \mathrm{i}: 8 \mathrm{~mA} / \mathrm{cm}^{2}$.

Figura 7: Influência da temperatura e densidade de corrente na estrutura do $\mathrm{MnO}_{2}$ obtido em solução $1 \mathrm{M}$ de $\mathrm{MnSO}_{4}$ e $0,68 \mathrm{M}$ de $\mathrm{H}_{2} \mathrm{SO}_{4}$.

A Figura 8 apresenta um difratograma típico para as amostras de $\mathrm{MnO}_{2}$ produzidas sob as diferentes condições testadas, tendo sido identificada apenas a presença da variedade alotrópica $\mathrm{MnO}_{2}-\varepsilon$, desejável para a fabricação de pilhas. 


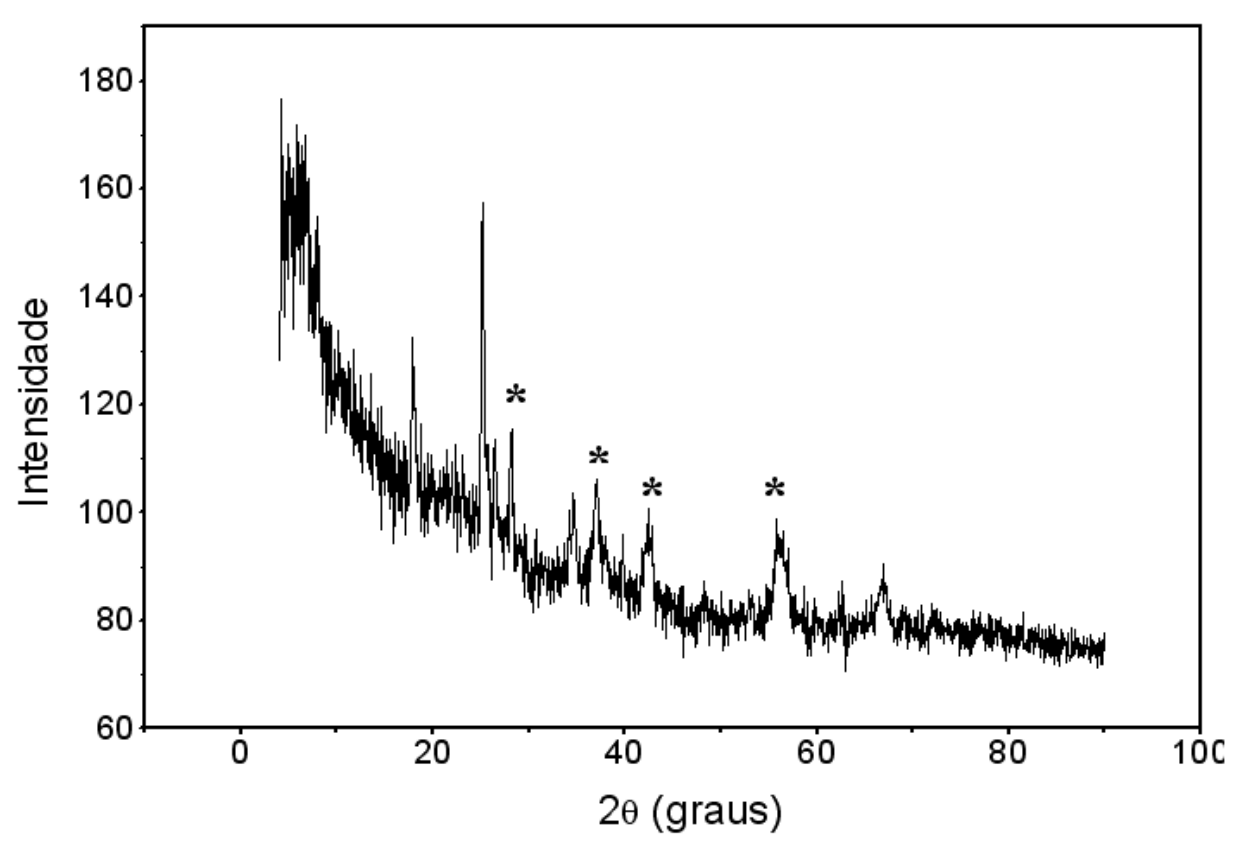

Figura 8: Difratograma típico dos depósitos de $\mathrm{MnO} 2$ (radiação $\mathrm{CuK \alpha}$.)

* Picos característicos do $\mathrm{MnO} 2$ - $\varepsilon$.

\section{CONCLUSÕES}

Os resultados obtidos indicaram que:

O aumento da temperatura diminui o fenômeno de passivação dos anodos de titânio durante a obtenção do dióxido de manganês.

$\mathrm{O}$ aumento da densidade de corrente e a diminuição da temperatura do eletrólito favorecem a obtenção de dióxido de manganês com maior área superficial, devido à formação de depósitos dendríticos.

A maior área superficial dos grãos de $\mathrm{MnO}_{2}$, de $168,0 \mathrm{~m}^{2} / \mathrm{g}$, foi obtida com uma densidade de corrente de $8 \mathrm{~mA} / \mathrm{cm}^{2}$, a $65^{\circ} \mathrm{C}$ e uma concentração de |ácido sulfúrico de $0,34 \mathrm{M}$.

A menor área superficial dos grãos de $\mathrm{MnO}_{2}$, de $51,8 \mathrm{~m}^{2} / \mathrm{g}$, foi obtida com uma densidade de corrente de $4 \mathrm{~mA} / \mathrm{cm}^{2}$, a $90^{\circ} \mathrm{C}$ e uma concentração de lácido sulfúrico de $0,34 \mathrm{M}$.

A influência da concentração de ácido sulfúrico na área superficial do depósito não é marcante, sendo mascarada pela influência da densidade de corrente e temperatura da solução.

Os resultados da difração de raios-X indicaram a presença de $\mathrm{MnO}_{2}-\varepsilon$, forma desejável para a fabricação de pilhas alcalinas de $\mathrm{Zn}-\mathrm{MnO}_{2}$ e de Leclanché.

\section{AGRADECIMENTOS}

Os autores expressam seu reconhecimento aos doutores Arnaldo Alcover Neto, Reiner Neumann e a química Antonieta Middea, do CETEM pela colaboração em parte das análises por microscopia eletrônica e pelas análises por BET.

6

BIBLIOGRAFIA

[1] PLETCHER, D., WALSH, F.C., Industrial Electrochemistry, 2 ed., London, Chapman and Hall, 1990.

[2] MATSUKI, K., ENDO, T., KAMADA, H., "SEM Studies of Electrolytic Manganese Dioxide", Electrochimica Acta, v. 29, n. 7, pp. 983-993, Jul. 1984.

[3] HINE, F., Electrode Processes and Electrochemical Engineering, New York, Plenum Press, 1985. 
[4] LAURINDO, E.A., AMARAL, F.A., SANTOS, M.L. et al., "Produção de Dióxido de Manganês Eletrolítico para Uso em Baterias de Lítio”, Química Nova, v. 22, n. 4, pp. 600-604, Jul/Ago 1999.

[5] RETHINARAJ, J.P., VISVANATHAN, S., "Anodes for Preparation of EMD and Application of Manganese Dioxide Coated Anodes for Electrochemicals", Materials Chemistry and Physics, v. 27, n. 4, pp. 337-349, Apr. 1991.

[6] RETHINARAJ, J.P., VISVANATHAN, S., "Preparation and Properties of Electrolytic Manganese Dioxide”, Journal of Power Sources, v. 42, n. 3, pp. 335-343, Feb. 1993.

[7] GHAEMI, M., BINDER, L. "Effects of Direct and Pulse Current on Electrodeposition of Manganese Dioxide”, Journal of Power Sources, v. 111, n. 2, pp. 248-254, Sep. 2002.

[8] IVES, J. G., JANZ, G. J., Reference Electrodes Theory and Practice, New York, Academic Press, 1961.

[9] WALSH, F.C., HERRON, M.E., "Electrocrystallization and Electrochemical Control of Crystal Growth: Fundamental Considerations and Electrodeposition of Metals", J. Phys. D: Applied Physics, v. 24, n. 2, pp. 217-225, Feb. 1991. 